\title{
EL REFRÁN COMO ESTRATEGIA COMUNICATIVA: (DES)CODIFICACIÓN DEL SENTIDO Y FUNCIÓN PRAGMÁTICO-DISCURSIVA
}

\begin{abstract}
Xavier Pascual López, El refrán como estrategia comunicativa: (des)codificación del sentido y función pragmático-discursiva [Proverbs as a Communication Strategy: (De)codification of Meaning and Pragmatic-Discursive Function], Studia Romanica Posnaniensia, Adam Mickiewicz University Press, Poznań, vol. XLI/1: 2014, pp. 17-30. ISBN 978-83-232-2673-4. ISSN 0137-2475. eISSN 2084-4158. Doi: 10.7169/strop2014.411.002
\end{abstract}

The aim of this paper is to provide a comprehensive, theoretical overview of how proverbs are used as a communicative and discursive strategy, taking into account the speaker's communicative intention. I will pay attention both to the benefits of the use of this type of formulaic sequence in the construction of the speech, and to the illocutionary force and pragmatic implications entailed by these utterances. In order to do so, some considerations will be required - the encoding of the meaning of the proverbs, the decoding process by the addressee, and the way proverbs are inserted in the discourse. This paper inspects the importance of such factors as the need for articulation of fluent speech, the assumption of cultural patterns, the appeal to proverbiality that aligns the speaker with power structures of the community, or the masking of the speaker's voice behind a collective entity in order to socialize and release tensions related to interpersonal contact.

Keywords: proverbs, paremiology, pragmatics, meaning encoding, meaning decoding, speech acts

\section{INTRODUCCIÓN}

Muy frecuentemente, los estudios paremiológicos españoles versan sobre las características formales de los refranes, centrándose en detalladas descripciones de peculiaridades fónicas (rima, ritmo, distribución acentual, entonación, aliteración, onomatopeyas...), léxicas (arcaísmos, latinismos, dialectalismos, palabras diacríticas, neologismos...) o morfosintácticas y estructurales (brevedad, elipsis, número de hemistiquios, paralelismos, esquemas estructurales, especificidades de los tiempos verbales... $)^{1}$, así como mezclándose a menudo con ciertas cuestiones semánticas que

${ }^{1}$ Sobre cuestiones formales de los refranes, pueden consultarse las aportaciones de Lázaro Carreter (1980), Peira (1988), García-Page Sánchez (1990a, 1990b, 1997), Olivera Soto (1996) o Hernando Cuadrado (1997), pero para una relación exhaustiva, consúltese Hernando Cuadrado (2010: 75-105), y para un muy completo análisis de los esquemas estructurales del refranero hispano, véase Pérez Martínez (1996: 197-258). 
atañen especialmente a recursos retóricos (metáforas, metonimias, comparaciones, antítesis, paradojas, hipérboles, personificaciones...).

Sin embargo, a nuestro modo de ver, este enfoque formal - con cierto tinte literario - ofrece un retrato parcial de las paremias, puesto que parece acercarse a los refranes como si fueran meros fósiles lingüísticos que la comunidad ha forjado a lo largo de largas tradiciones culturales y folklóricas, pasando por alto su uso efectivo en el discurso de los hablantes: qué mecanismos entran en juego para decidir su empleo, cómo se engarzan en el discurso, qué tipos de actos de habla constituyen, qué factores influyen en la codificación y la descodificación de su sentido, qué implicaciones pragmáticas tiene su uso, etc.

Por tanto, el objetivo de este artículo será ofrecer una visión panorámica de cómo el refrán es empleado como estrategia discursiva, teniendo en cuenta la intención comunicativa que el hablante tiene en mente, tanto en cuanto a las ventajas que ofrece el recurso a este tipo de fraseologismo para la construcción del discurso, como en cuanto a la fuerza ilocutiva y las implicaciones pragmáticas que encierra y que son imprescindibles para su utilización y su interpretación ${ }^{2}$.

\section{RELEVANCIA DISCURSIVA DE LOS ASPECTOS FORMALES}

El antropólogo y folklorista Richard Bauman (1975) proyectó una satisfactoria teoría en la que todas estas cuestiones formales descritas por los paremiólogos cobran sentido desde una perspectiva comunicativa: los refranes (como otros productos del arte verbal propios de la tradición oral) constituyen una alteración de la forma convencional de expresión adoptada por la mayoría de los comunicados lingüísticos, de modo que el receptor debe abandonar el marco interpretativo neutro con el que descodifica generalmente los mensajes y sustituirlo por el propio de la performance ${ }^{3}$, que deja de lado los usos referenciales del lenguaje y se centra en su función poética. Para que, en la descodificación, pueda efectuarse este cambio de marco interpretativo, en la codificación se empleará un conjunto estructurado de medios comunicativos que se entenderán como claves para guiar la adecuada interpretación, y entre estas claves se hallarán las peculiaridades formales y semánticas propias de los refranes y que tan a menudo han sido detalladas.

De entre todos los medios descritos por Bauman (1975: 295), los que mejor se ajustan al caso particular de los refranes son los siguientes: los códigos especiales (palabras diacríticas, arcaísmos, dialectalismos...), las fórmulas especiales que los

${ }^{2}$ Debido a limitaciones de espacio, la exposición se fundará en una revisión teórica, ilustrada con algunos ejemplos pero sin un estudio de campo que habría requerido mayores dimensiones y que, en futuras publicaciones, complementará las disquisiciones contenidas en el presente artículo.

${ }^{3}$ Para el concepto de performance como una manera marcada de expresarse que necesita un marco interpretativo específico, véanse Bauman (1986: 3) y Bauman y Briggs (1990: 73). 
introducen y advierten de su naturaleza (los llamados marcadores mediativos o de cita, a los que luego nos referiremos), el lenguaje figurativo (con diversos tipos de tropos y otras figuras retóricas), diversos recursos estilísticos (rima, aliteración, paralelismo...), patrones prosódicos especiales (entonación y ritmo específicos) y llamamientos a la tradición (alusiones a su antigüedad, tradicionalidad y veracidad comprobada). A estos factores, podríamos añadir otro que Norrick (2007: 385) aduce para dar cuenta de los motivos por los cuales se reconocen los refranes: que ocupan posiciones discursivas destacadas (resúmenes de ideas, cierres de historias con una función evaluativa, topoi especializados en argumentaciones, etc.).

En consecuencia, podemos entender que la complejidad formal de los refranes responde al objetivo de captar la atención del receptor, quien, para poder descifrar el mensaje recibido, quedará pendiente de todo lo que diga y haga su interlocutor. A su vez, a través de este desequilibrio en el rol del intercambio comunicativo, el emisor adquiere un prestigio que se ampara en la especificidad de su discurso y que se escuda en su apelación a la tradición, convirtiéndose en quien controla la interacción y llegando a adquirir la capacidad de transformar la estructura social a través de su acto de habla (Bauman, 1975: 304-305).

\section{INSERCIÓN DEL REFRÁN EN EL DISCURSO}

Siguiendo la estela de Bauman, Briggs (1985: 798-802) establece una serie de rasgos comunicativos que caracterizan pragmáticamente la performance de los refranes, si bien sólo algunos de ellos son obligatorios (marcados con asterisco): (1) la frase-vínculo que une el discurso precedente al refrán que introduce; $(2 *)$ la identificación de la persona, instancia o tradición con la que se asocia el refrán (aunque puede producirse de forma muy vaga y general); $\left(3^{*}\right)$ el aspecto de cita a través de algún verbo dicendi, con lo que - junto con lo anterior - se le otorga legitimidad y autoridad; (4*) el refrán propiamente dicho; (5) ciertas asociaciones especiales (indicación de su origen, vinculación a un grupo, etc.); (6) apelación a su sentido general (a menudo a modo de paráfrasis, con explicitación de sus implicaciones, implicaturas o situaciones en las que se aplica); (7) relevancia respecto al contexto y a la situación presente para orientar su descodificación; y $\left(8^{*}\right)$ la validación del refrán por parte del receptor, quien deberá ratificar la validez o adecuación del mismo a través del sentimiento de verdad que el emisor quería despertar en él (Veyrat Rigat, 2008: 9) ${ }^{4}$.

Muchos de estos aspectos (en especial 1-3, pero no sólo) se concretan en lo que se ha denominado marcadores mediativos o de cita, cuya función comunicativa es

\footnotetext{
${ }^{4}$ De todos modos, más que de obligatoriedad, debería hablarse de rasgos con una alta frecuencia de aparición, pues en ocasiones el refrán es introducido sin más elementos accesorios, a la espera de que se produzca la validación por parte del interlocutor para que el acto de habla se realice de forma efectiva.
} 
señalar el origen de un texto o de una opinión que se está evocando en el propio discurso (Anscombre, 2010: 24). A través de estos marcadores discursivos que incluyen verbos dicendi, se remite a una fuente de información que, en el caso de los refranes, apela o bien a un enunciador identificado (Como decía mi abuelo...) o bien a uno indeterminado, general y anónimo (Ya sabes lo que dicen/se dice..., Como suele decirse..., Como dicen...), a veces concretado en la propia naturaleza del refrán como fuente de autoridad (Como dice el refrán...). Asimismo, el marcador mediativo suele incluir la actitud del locutor respecto al contenido del refrán, que suele compartir, pero del que en realidad podría distanciarse o incluso desentenderse, si bien tal no es el caso más habitual (salvo en el uso de refranes en contraargumentaciones).

Analizando estos marcadores en un corpus de español hablado, Penadés Martínez (2006: 295) constata que, en cuanto a su estructura morfosintáctica, pueden ser nominales, verbales o polilexicales. Por otro lado, desde una perspectiva discursiva, contempla que no sólo preceden la paremia, sino que también la suceden (mostrando, respectivamente, deixis catafórica o anafórica), al tiempo que a veces subrayan características que se asignan intuitivamente a los refranes (valor de ley o verdad universal, tradicionalidad, atemporalidad, laconicidad, etc.), de modo que ofrecen la posibilidad de poner énfasis en su uso como argumentos o en sus peculiaridades formales, potenciando el marco interpretativo adecuado.

A su vez, Almela Pérez y Sevilla Muñoz (2000: 25) señalan que los marcadores de cita no son los únicos conectores capacitados para introducir los refranes, indicando que también pueden ser de argumentación o de deducción. Aunque no lo concretan, está claro que el empleo de estos conectores está relacionado con la función argumentativa que se asigna al refrán en el discurso, presentándose como un puntal sobre el que se basa un razonamiento o como una conclusión que viene a ratificar lo que se ha expuesto anteriormente.

\section{SENTIDO Y FUNCIÓN COMUNICATIVA DEL REFRÁN}

En cuanto a la naturaleza del sentido de los refranes, existen dos posturas radicalmente opuestas. Algunos paremiólogos, escudándose en la autonomía sintáctica propia de las paremias, consideran que estas unidades constituyen textos o enunciados por sí mismas, de manera que las consideran unidades libres no condicionadas que pueden ser comprendidas cabalmente sin tener en cuenta ni el contexto lingüístico, ni el extralingüístico y la situación comunicativa, puesto que entienden que son los propios refranes los que actúan sobre el contexto a modo de comentario al insertarse en el interior de otros textos (Zuluaga, 1980: 201; Hernando Cuadrado, 1990: 542, 2010: 45).

Esta perspectiva contrasta fuertemente con la consideración de que los refranes, en realidad, adquieren sentido en su ejecución lingüística, con lo cual se convierten 
en enunciados condicionados por el contexto en el que aparecen. El referente de este posicionamiento es el ya clásico artículo de Kirshenblatt-Gimblett (1973), que se sustenta en una de las tendencias más habituales en la paremiología anglosajona: la consideración casi exclusiva de los refranes como unidades figurativas, incluyéndolos a menudo en la categoría fraseológica de los idioms. Según esta teoría, los refranes están provistos de múltiples sentidos potenciales, cuya concreción sólo puede percibirse a través de su uso, de modo que el análisis de su sentido deberá contemplar la imagen figurada presentada por la unidad, el principio general al que hace referencia, la evaluación del mismo que realiza el propio refrán y las exigencias particulares de la situación en la que se emplea. De hecho, con excepción del primero, estos pasos necesarios para su interpretación son también aplicables a los refranes no figurativos.

Pese a lo muy discordantes que ambas posturas podrían parecer, en verdad tanto una como la otra tienen su clara razón de ser. Ante todo, no hay que pasar por alto que los refranes están dotados de un sentido general o germinal, lo que Almela Pérez y Sevilla Muñoz (2000: 9) denominan «un significado invariante» que, por ejemplo, hace posible clasificarlos según criterios temáticos, incluso que pueda llegar a definirse su significado o a parafrasearse su valor informativo.

Además, la modalidad de la enunciación de los refranes proporciona a priori información general sobre su sentido o su intención comunicativa, con independencia del contexto. A este respecto, a menudo se distingue entre refranes descriptivos, que se entienden como actos de habla representativos que constatan aserciones cuya verdad se acepta, y refranes prescriptivos, que constituyen un acto de habla directivo con el objeto de influir en el receptor (Conca, 1990: 27-30; Penadés Martínez, 2006: 295-296) $)^{5}$

Por su parte, Almela Pérez y Sevilla Muñoz (2000: 20) contemplan estas dos orientaciones de la modalidad enunciativa de las paremias (aunque las llaman asertiva y actuativa, respectivamente) y añaden una tercera, la modalidad valorativa, a través de la cual se emiten juicios de valor. A partir de estas tres modalidades, distinguen cinco funciones comunicativas básicas: de la modalidad asertiva, (1) la constatación de la (in)existencia de algo; de la actuativa, (2) la persuasión y (3) la disuasión respecto a comportamientos; de la valorativa, (4) el elogio y (5) el vituperio de realidades y conductas. Otras funciones comunicativas (informar, amenazar, insultar, aconsejar, exhortar, expresar conformidad, rechazo, resignación, etc.) son reducibles, en realidad, a estas cinco.

Con todo, desde la perspectiva que les daba la etnografía de la comunicación, Arewa y Dundes (1964) fueron pioneros en dar importancia al contexto de uso de las paremias, gracias al cual no sólo puede describirse su función de forma abstracta, sino que el análisis está facultado para dar cuenta de su función particular en una situación

${ }^{5}$ No obstante, como se verá más adelante, la mayoría de los actos de habla que constituyen los refranes son directivos, pese a que aparentemente tengan aspecto de aseveraciones y se presenten como descriptivos. 
comunicativa concreta en la que la voluntad de unos hablantes determinados se erige en fundamental. De este modo, pese a que toda esta información semántico-pragmática es deducible de la mera formulación de los refranes, no hay que perder de vista que, de hecho, su correcta interpretación debe depender del contexto lingüístico en el que se insertan y del contexto situacional en el que se emplean. Esto se debe a que sólo en su empleo puede perfilarse y percibirse la verdadera intención con la que el hablante recurre a ellos, en tanto que la fuerza ilocutiva de los refranes no depende del refrán en sí (provisto de dicho sentido básico), sino que dimana del acto de habla que constituye $y$, por ende, de las presuposiciones de los interlocutores que entran en juego en el intercambio comunicativo y que posibilitarán que se logre el efecto perlocutivo que se persigue con dicho acto de habla (Conca, 1990: 24-27; Veyrat Rigat, 2008: 20-21; Norrick, 2007: 381-382).

\subsection{CODIFICACIÓN Y DESCODIFICACIÓN DEL SENTIDO DE LOS REFRANES}

Centrándose en el proceso de interpretación de los refranes, Seitel (1969), en su también clásico artículo, argumenta que se funda en una serie de procedimientos comparativos, concibiendo el refrán como una analogía en la que se establecen asociaciones simbólicas entre dos dominios mentales: la paremia, en su formulación, plantea una situación particular que debe ponerse en relación con lo que Seitel llama «situación social», entendida como un dominio abstracto instituido sobre un conjunto de normas actitudinales reconocidas a nivel social por la comunidad de habla, así como sobre todo un sistema de asociaciones culturalmente específicas compartidas por el mismo grupo humano y que permiten interpretar el lenguaje figurativo de forma adecuada.

Por tanto, las paremias remiten a una serie de pautas sociales y asociaciones ideológicas condicionadas por la cultura, a través de las cuales se codifica y se descodifica el sentido de los refranes. Ampliando esta teoría, Wotjak (2005: 141-142) sostiene que, para la interpretación de los fraseologismos idiomáticos, los recursos habituales de los tropos no bastan para caracterizar los mecanismos de la generación de su sentido, pues entra en juego un heterogéneo repertorio de entidades cognitivas, es decir, representaciones que han ido almacenándose en nuestra memoria a medida que se ha ido trabando nuestra formación social, cultural y empírica mediante la interacción social y nuestra relación con el mundo exterior. Toda esta información condicionada social y culturalmente ${ }^{6}$ es asimilada en la forma de configuraciones cognitivas, las cuales permiten que pueda establecerse una serie de inferencias en las que se

\footnotetext{
${ }^{6}$ Así y todo, desde la visión universalista que conlleva la perspectiva cognitivista, Telija et al. (1998: 66) afirman que la conceptualización que toma el lenguaje figurativo como recurso no tiene por qué estar culturalmente determinada, aunque que no lo esté siempre no es óbice para que pueda estarlo en ocasiones.
} 
combinan diversas de ellas y a través de lo cual se hace posible tanto la codificación como la descodificación del sentido de los refranes.

Honeck (1997: 128-133) formula una teoría cognitiva en torno al funcionamiento de los refranes llamada «Extended conceptual base theory», según la cual se puede detectar una serie de pasos para que el uso de un refrán como estrategia comunicativa sea exitoso desde el punto de vista de su recepción. En primer lugar, la unidad se entiende en sentido literal, el cual generalmente carece de razón de ser al no parecer relevante en relación con el contexto en el que se emplea, de modo que no encaja en el entorno cognitivo de la situación. Este problema — que atenta contra la máxima de relación del principio de cooperación de Grice (1975: 45-47) que induce a que los interlocutores digan cosas relevantes - hace que el receptor se plantee reinterpretar el mensaje recibido e intente reconciliar el refrán con el contexto situacional a través de la deducción de una serie de implicaturas. En este proceso, se sigue lo que Honeck denomina «ostension maximization principle», principio que sostiene que hay que extender el significado de un mensaje más allá de su literalidad para que adquiera un sentido más amplio o general. Una vez se ha llegado a esta generalización, es posible atribuirle a la paremia un sentido traslaticio, dado que se ha puesto en marcha el pensamiento abstracto mediante las asociaciones e inferencias que han posibilitado el paso de lo literal a lo general. Alcanzado este punto, el receptor puede reconocer el sentido del refrán y, por ende, conectarlo con el contexto.

En consecuencia, desde el punto de vista conceptual, los refranes responden a un proceso de generalización a partir de observaciones particulares, por cuanto reinterpretan acciones o hechos concretos en términos de modelos compartidos por la comunidad de habla. De este modo, los refranes son fruto de las estructuras culturales, pero al mismo tiempo conciernen a la evaluación de ciertos modelos de conducta — que acaban perfilando, configurando y perpetuando-, lo cual se consigue, pragmáticamente, a través de actos de habla directivos indirectos, que a menudo se presentan formalmente como descripciones generalizadas pero que en su fondo persiguen tener el efecto de sugerencias, consejos, recomendaciones o incluso órdenes (White, 1987: 151-152).

En conclusión, podemos afirmar que, como formas de conocimiento generalizado, los refranes reflejan unos modelos culturales de la experiencia que son los que aportan una especie de guía interpretativa que conducen al receptor a ese sentido germinal que mencionábamos, a partir del cual cabe la posibilidad de que sea modificado o reelaborado en los contextos de uso particulares. En vista de que los refranes no suelen tener una interpretación literal, sino que cuando menos son indirectos y a menudo parciales (cuando no directamente figurativos), su comprensión requiere que se realice un proceso de inferencia de las implicaciones adecuadas a cada refrán y a cada contexto mediante conocimientos previos al acto de comunicación y a toda una serie de asunciones subyacentes, en los que entran cosmovisiones particulares, 
ideas preconcebidas, prejuicios, estereotipos, símbolos y connotaciones culturales, actitudes sociales, modelos de conducta y de interacción, etc.

Tanto Seitel (1969) como posteriormente White (1987: 154-155) señalan que la mayoría de los refranes, en su codificación, remite a cuestiones sociales y morales a través de la conexión entre rasgos concretos de las situaciones sociales en las que se verbalizan y otros dominios más mundanos, más cotidianos, que poseen unas implicaciones conceptuales claramente definidas y dilatadamente conocidas en la comunidad de habla. Este proceso, en su día, fue denominado «catálisis cultural» por Marsá (1972), quien lo entendía como la transferencia de conceptos de un orden común a otros de índole abstracta y universal, a través del recurso a la experiencia cotidiana compartida por la comunidad para la formulación de su contenido proposicional (es decir, en su literalidad), cuyo sentido queda claramente subordinado al translaticio, hasta el punto de que puede llegar a emplearse sin que se conozca la realidad a la que alude en su literalidad y que le dio origen (por ejemplo, la náutica o la tauromaquia).

\subsection{FUNCIÓN DISCURSIVA DE LOS REFRANES}

En realidad, de todos los mensajes indirectos y figurativos, los pertenecientes al lenguaje formulario o discurso prefabricado (en el que inscriben los refranes) son los más interiorizados y automatizados, de manera que no tienen que ser reconstruidos cada vez que se usan, sino que su sucesiva repetición favorece su interpretación en los nuevos contextos de uso en que aparecen. De hecho, desde los primeros estudios en torno al lenguaje formulario se puso de relieve la idea de que éste asegura la fluidez de la ejecución lingüística, por lo que se recurre a este tipo de expresión prefabricada por motivos de economía y rapidez en la codificación de los mensajes, en tanto que se ejecutan y procesan con mayor fluidez que las combinaciones libres.

De esta forma, las secuencias formularias (incluidos los refranes y el resto de expresiones fraseológicas) constituyen una especie de armazón en el que se ampara la codificación de la mayoría de los mensajes. A este respecto, podemos tomar en consideración dos hipótesis planteadas desde Norteamérica. Por un lado, Pawley y Syder $(1983,2000)$ propusieron la «one clause at a time hypothesis», una teoría que pone en duda que los hablantes puedan codificar espontánea, fluida y coherentemente un mensaje con estructuras sintácticas complejas empleando sólo combinaciones léxicas no preestablecidas, cuyo uso exclusivo convertiría cualquier discurso en titubeante, inconexo y descohesionado.

Por otro lado, amparándose en la idea de que el cerebro humano difícilmente se centra en dos cuestiones a la vez, la «focusing hypothesis» de Wray (1992: 160) mantiene que, tanto en la codificación como en la descodificación de los mensajes lingüísticos, los hablantes pueden procesar la información de forma analítica u holística, siendo la segunda la que, por economía de esfuerzo, generalmente se prefiere. No 
obstante, cuando hay que pasar de una cláusula a la siguiente, se requiere un nivel de análisis más atomista (por tanto, analítico), lo cual puede acarrear esa falta de fluidez que apuntaban Pawley y Syder $(1983,2000)$. Dado que las secuencias formularias como los refranes no necesitan ser generadas, no requieren del hablante que se ocupe de dos tareas de forma simultánea, de modo que es capaz de expresarse más fluidamente si las emplea (Wray y Perkins, 2000).

Atendiendo al papel que las secuencias formularias desempeñan en la consecución de la fluidez, Wray y Perkins (2000: 15-17) detallan tres funciones primordiales sobre las cuales, para estos autores, se funda una taxonomía de unidades formularias tripartita: unidades destinadas (1) a incrementar la rapidez y la fluidez de la producción lingüística, (2) a ganar tiempo durante la ejecución, y (3) a obtener acceso a información que no sería recordada de otro modo y tener la posibilidad de retenerla. Si bien en el caso de los refranes estas distinciones no sirven para clasificarlos, sí hay que tener en cuenta que las tres funciones descritas se adecuan a su empleo y su efecto en la construcción de un discurso fluido.

Por consiguiente, puede aseverarse que el hecho de acudir al empleo de refranes y otros ítems lingüísticos formularios en aras de la fluidez equivale, en cierta medida, a adoptar y acomodarse a modos preestablecidos de formular lo que se quiere comunicar (Pawley, 2007: 22; Lee, 2007: 471).

Los mismos autores que proponían las tres funciones mencionadas en torno a la fluidez, brindan tres funciones más que se aplican exclusivamente a las unidades de índole predominantemente interaccional (Wray y Perkins, 2000: 17-18; Wray, 2002: 93-97): (1) influir en el interlocutor (dar órdenes, dar consejos, hacer peticiones, establecer acuerdos...); (2) afirmar identidades separadas (por ejemplo, reclamar el turno de habla); (3) afirmar la identidad del grupo como una unidad (mediante cánticos grupales, textos rituales, unidades como paremias que remiten a un acervo o una tradición comunes, formas de tratamiento...). De estas tres, la segunda es más difícilmente aplicable a los refranes, pero las otras dos se corresponden innegablemente con ellos.

En otro orden de cosas y teniendo en cuenta todo lo anterior, Wray (2002: 96-98) considera que los objetivos comunicativos básicos de toda interacción se reducen a tres: (1) referir datos, (2) influir en el interlocutor y (3) acceder a información almacenada. Todos estos objetivos pueden cumplirse tanto mediante lenguaje nuevo (combinaciones libres) como lenguaje formulario, pero algunos de ellos favorecen un tipo u otro de lenguaje: el primero es el que tiene más probabilidades de construirse de forma nueva, pues un mensaje referencial a menudo así lo requiere; el segundo hace más factible las secuencias prefabricadas que faciliten la codificación/descodificación $\mathrm{y}$, con ello, la consecución del objetivo buscado; y el último se realiza íntegramente mediante secuencias formularias. Así se refleja en el siguiente esquema elaborado por la propia Wray (2002: 98): 


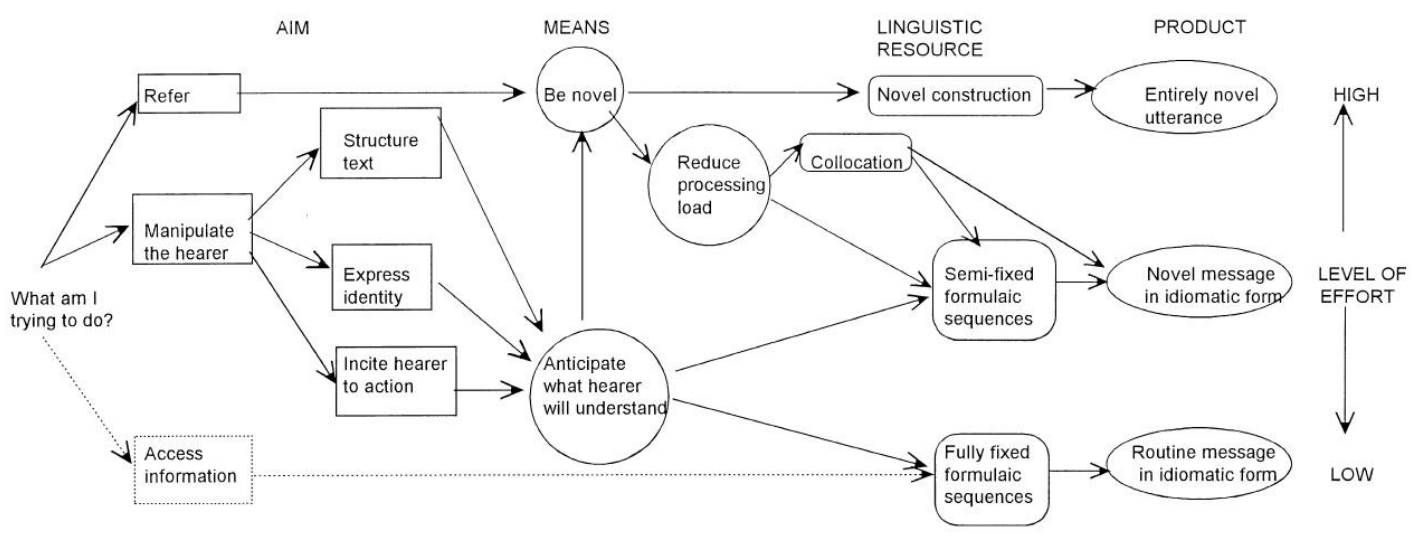

Esquema del uso de las secuencias formularias según el objetivo comunicativo del hablante (Fuente: Wray, 2002: 98)

En conclusión, podemos afirmar que la función de los refranes en el discurso responde a dos niveles diferentes: por un lado, la funcionalidad que el recurso al lenguaje prefabricado en general adquiere en la construcción de todo discurso, con toda una serie de ventajas respecto a las construcciones libres (calidad de un discurso fluido y seguro, rapidez en el proceso de codificación y descodificación, fácil acceso a información aprendida y asumida, apelación a la unidad de la colectividad y a un acervo ideológico compartido sancionado por la tradición); y por otro, la función comunicativa específica que cada refrán desempeña cuando se inserta en el discurso constituyendo un acto de habla indirecto predominantemente directivo, teniendo presente la posibilidad de su plurifuncionalidad (discursiva, textual, interaccional, conativa, expresiva, referencial, poética, etc.).

Para que esta función más específica pueda cumplirse de forma satisfactoria, para que el proceso de descodificación y comprensión del refrán tenga lugar y para que el empleo de la paremia surta el efecto perseguido por el emisor, el receptor deberá descodificar su estructura analógica y relacionarlo con el contexto, con el objeto de entresacar implicaturas evaluativas y conductuales y extraer una interpretación particular de la situación.

Estudiando el uso real de refranes en una comunidad hispana, Domínguez Barajas (2010: 104) constata, como resultado de su análisis, que se emplean a modo de herramientas de socialización, a menudo como estrategias indirectas para criticar algo o a alguien que no se amolda a los modelos y valores socioculturales compartidos por la comunidad. Con anterioridad, Arewa y Dundes (1964: 71) se habían dedicado a analizar los contextos de uso de las paremias, concluyendo que se dan en situaciones comunicativas caracterizadas por un contacto interpersonal cercano y que se emplean a guisa de estrategias cuyo objeto es sobrellevar situaciones típicas, cotidianas y recurrentes, en las que se generan tensiones que las paremias contribuyen a aliviar. 
Este efecto paliativo se obtiene gracias a que el refrán apela a la proverbialidad como fuente de autoridad, a ese enunciador indeterminado, general y anónimo que se reconoce como la propia colectividad con la que los interlocutores se identifican o a la que se someten, confiriendo a los refranes la venerabilidad con la que se acostumbran a escuchar y dotándolos de esa fuerza probativa y comprobativa (Veyrat Rigat, 2008: 9). Asimismo, esta apelación al grupo y a la colectividad suprapersonal convierte el acto de habla en indirecto y tiene como resultado la despersonalización de la crítica emitida. Saville-Troike (2003: 29) indica que esto se corresponde con la consideración del refrán como una enunciación-eco, de modo que, como cualquier cita, el refrán se convierte en una unidad polifónica (Manero Richard, 2005), ya que en su ejecución el locutor no coincide con el autor — que se entiende como una conciencia lingüística colectiva- $y$, por ende, el hablante se ve libre de adherirse o no a la carga moral y cultural, así como de asumir la responsabilidad de la crítica que implica su enunciado.

\section{CONCLUSIONES}

Por todo ello, el refrán como estrategia comunicativa suele tener como fin la preservación de la imagen pública ${ }^{7}$ del hablante, en tanto que evita que éste se convierta en el blanco de sentimientos negativos por parte de su interlocutor. Al ampararse en la colectividad y recurrir a una secuencia formularia que remite a modelos socioculturales compartidos, la crítica se desvanece como un juicio personal y se convierte en una necesidad surgida de las expectativas de la comunidad. Y además, como el proceso de descodificación requiere que se vuelva la mirada hacia los dictámenes de la comunidad, hace que el interlocutor participe en la creación del sentido, puesto que, como miembro de dicha comunidad, tiene asumidos los patrones culturales comprendidos en el refrán y se deja guiar por los lazos de solidaridad que le unen a lo colectivo.

De esta forma, utilizando paremias en su discurso, los hablantes ocultan sus propios sentimientos, su propia intimidad, velada detrás de la opinión de la comunidad entera; pero, al mismo tiempo, los refranes constituyen una vía de escape para todos esos sentimientos negativos que surgen, necesariamente, del contacto humano y de las relaciones interpersonales, en tanto que se hace tolerable la crítica sin perjuicio a la propia imagen.

Además, al apelar a lo colectivo, el hablante se alinea con las estructuras de poder tradicionales, de manera que se sitúa en una posición superior respecto a su interlocutor (Norrick, 2007: 386), lo cual lo capacita para llegar a transformar la realidad social, tal como sostenía Bauman (1975), pues con su empleo de la lengua tiene la

7 Tomando como referente a Escandell Vidal (1999: 148), con este término nos referimos en español a la noción de face dentro de la conocida teoría de Brown y Levinson (1987), es decir, ese prestigio que todo hablante pretende salvaguardar, necesidad de la que dimanan las estrategias propias de la cortesía y de los modos de hablar indirectos. 
posibilidad de manipular a sus prójimos y condicionar su comportamiento. Y esto no sólo se consigue mediante la constitución de actos de habla directivos que persiguen un claro efecto perlocutivo en el destinatario, sino también a través de refranes que, aparentemente, constituyen actos de habla representativos, en tanto que estos refranes obedecerán a una perspectiva concreta (pues la experiencia lingüísticamente condicionada es subjetiva por definición) que podrá llegar a modificar la percepción de la realidad por parte de su destinatario.

\section{BIBLIOGRAFÍA}

Almela Pérez, Ramón; Sevilla Muñoz, Julia (2000): «Paremiología contrastiva: Propuesta de análisis lingüístico». Revista de investigación lingüística, 3/1: 7-47.

Anscombre, Jean-Claude (2010): «Las formas sentenciosas: un fenómeno lingüístico». Revista de Investigación Lingüistica, 13: 17-43.

Arewa, E. Ojo; Dundes, Alan (1964): «Proverbs and the Ethnography of Speaking Folklore». American Anthropologist, 66/6/2: 70-85.

Bauman, Richard (1975): «Verbal Art as Performance». American Anthropologist, 77/2: 290-311.

Bauman, Richard (1986): Story, Performance, and Event: Contextualized Studies of Oral Narrative. Cambridge: Cambridge University Press.

Bauman, Richard; Briggs, Charles L. (1990): «Poetics and Performance as Critical Perspectives on Language and Social Life». Annual Review of Anthropology, 19: 59-88.

Briggs, Charles L. (1985): «The Pragmatics of Proverb Performances in New Mexican Spanish». American Anthropologist, 87/4: 793-810.

Brown, Penelope; Levinson, Stephen C. (1987): Politeness: Some Universals in Language Usage. Cambridge: Cambridge University Press.

Conca, Maria (1990): Paremiologia. Valencia: Universitat de València, $2^{\mathrm{a}}$ ed.

Domínguez Barajas, Elías (2010): The Function of Proverbs in Discourse: The Case of a Mexican Transnational Social Network. Berlín — Nueva York: Walter de Gruyter Mouton.

EsCANDELl VIDAL, Ma Victòria (1999): Introducción a la pragmática. Barcelona: Ariel, $2^{\mathrm{a}}$ ed.

García-Page Sánchez, Mario (1990a): «Propiedades lingüísticas del refrán (I)». Epos. Revista de Filología, 6: 499-510.

García-Page SÁnchez, Mario (1990b): «Aspectos fónicos en la configuración de los refranes». Notas y Estudios Filológicos, 5: 75-121.

García-Page SÁnchez, Mario (1997): «Propiedades lingüísticas del refrán (II): el léxico». Paremia, 6: 275-280.

Grice, H. Paul (1975): «Logic and Conversation». In: Peter Cole \& Jerry L. Morgan [ed.], Syntax and Semantics, vol. 9: Pragmatics, Nueva York: Academic Press, 41-58.

Hernando Cuadrado, Luis Alberto (1990): «Sobre las unidades fraseológicas en español». In: Ma Ángeles Álvarez Martínez [ed.], Actas del Congreso de la Sociedad Española de Lingüistica. XX Aniversario (Tenerife, 2-6 de abril de 1990), vol. 1. Madrid: Gredos, 536-547.

Hernando Cuadrado, Luis Alberto (1997): «Estilística del refrán». Paremia, 6: 327-332.

Hernando CuAdRado, Luis Alberto (2010): El refrán como unidad lingüistica del discurso repetido. Madrid: Escolar y Mayo Editores.

Honeck, Richard P. (1997): A Proverb in Mind. The Cognitive Science of Proverbial Wit and Wisdom. Mahwah - Londres: Lawrence Erlbaum Associates.

Kirshenblatt-Gimblett, Barbara (1973): «Toward a Theory of Proverb Meaning». Proverbium, 22: 821-827. 
LÁzaro CARreter, Fernando (1980): «La lengua de los refranes. ¿Espontaneidad o artificio?». In: Estudios de lingüistica. Barcelona: Crítica, 219-232.

LeE, Penny (2007): «Formulaic Language in Cultural Perspective». In: Paul Skandera [ed.], Phraseology and Culture in English. Berlín - Nueva York: Mouton de Gruyter, 471-496.

MANERo Richard, Elvira (2005): «Un caso especial de fenómeno polifónico de la lengua: el refrán». In: Manuel Casado Velarde, Ramón González Ruiz \& Óscar Loureda Lamas [ed.], Estudios sobre lo metalingüistico (en español). Frankfurt am Main - Berlín - Berna: Peter Lang Verlag, 93-115.

MARSÁ, Francisco (1972): «Catálisis cultural en conceptos semánticos». Ethnica. Revista de Antropología, 3: 85-98.

Norrick, Neal R. (2007): «Proverbs As Set Phrases». In: Harald Burger, Dmitrij Dobrovol'skiJ, Peter KÜHN \& Neal R. NoRRICK [ed.], Phraseology. An International Handbook of Contemporary Research, vol. 1. Berlín - Nueva York: Walter de Gruyter, 381-393.

Olivera Soto, Elena (1996): «Recursos estilísticos en el refranero». Paremia, 5: 199-202.

Pawley, Andrew (2007): «Developments in the Study of Formulaic Language Since 1970. A Personal View». In: Paul Skandera [ed.], Phraseology and Culture in English. Berlín - Nueva York: Mouton de Gruyter, 3-45.

Pawley, Andrew; Syder, Frances Hodgetts (1983): «Two Puzzles for Linguistic Theory: Nativelike Selection and Nativelike Fluency». In: Jack C. Richards \& Richard W. Schmidt [ed], Language and Communication. Londres: Longman, 191-227.

Pawley, Andrew; Syder, Frances Hodgetts (2000): «The One Clause at a Time Hypothesis». In: Heidi Riggenbach [ed.], Perspectives on Fluency. Ann Arbor, MI: University of Michigan Press, 167-191.

Peira, Pedro (1988): «Notas sobre la lengua de los refranes». In: Homenaje a Alonso Zamora Vicente I: Historia de la lengua. El español contemporáneo. Madrid: Castalia, 481-489.

Pérez Martínez, Herón (1996): El hablar lapidario: Ensayo de paremiología mexicana. Zamora: El Colegio de Michoacán.

Saville-Troike, Muriel (2003): The Ethnography of Communication. An Introduction. Malden, MA - Oxford: Blackwell Publishing, $3^{\mathrm{a}}$ ed.

Seitel, Peter (1969): «Proverbs: A Social Use of Metaphor». Genre, 2: 143-161.

Telija, Veronika N.; Bragina, Natalia; Oparina, Elena; Sandomirskaja, Irina (1998): «Phraseology as a Language of Culture: Its Role in the Representation of a Collective Mentality». In: Anthony P. CowIE [ed.], Phraseology. Theory, Analysis, and Applications. Oxford - Nueva York: Oxford University Press, 55-75.

Veyrat Rigat, Montserrat (2008): «Aproximación lingüística al estudio del refrán como unidad comunicativa». Dialogía, 3: 5-31.

WhITE, Geoffrey M. (1987): «Proverbs and Cultural Models. An American Psychology of Problem Solving». In: Dorothy Holland \& Naomi QuinN [ed.], Cultural Models in Language and Thought. Cambridge: Cambridge University Press, 151-172.

WотJAK, Gerd (2005): «¿Qué significado podemos atribuir a las unidades fraseológicas?». In: Juan de Dios Luque Durán \& Antonio Pamies Bertrán [ed.], La creatividad en el lenguaje: colocaciones idiomáticas y fraseología. Granada: Granada Lingvistica \& Método Ediciones, 121-147.

WraY, Alison (2002): Formulaic Language and the Lexicon. Cambridge: Cambridge University Press.

Wray, Alison; Perkins, Mick (2000): «The Functions of Formulaic Language: An Integrated Model». Language and Communication, 20/1: 1-28.

Zuluaga, Alberto (1980): Introducción al estudio de las expresiones fijas. Frankfurt am Main Berna - Cirencester: Peter Lang. 